\title{
Reseña de Juan Pérez de Montalbán, Comedias varias. Volumen 3.7, ed. Claudia Demattè, David Arbesú y Philip Allen, Kassel, Reichenberger (Colección Teatro del Siglo de Oro-Ediciones Críticas 209), 2016, 358 pp. ISBN: 978-3-944244-59-4
}

\section{José Elías Gutiérrez Meza}

Universidad de Piura/Pontificia Universidad Católica del Perú PERÚ

elias.gutierrez@udep.pe/jegutierrezm@pucp.edu.pe

[Hipogrifo, (issn: 2328-1308), 6.1, 2018, pp. 725-727]

Recibido: 09-01-2018 / Aceptado: 09-02-2018

DOI: http://dx.doi.org/10.13035/H.2018.06.01.50

Este volumen forma parte de la serie Obras de Juan Pérez de Montalbán que, bajo la dirección de Claudia Demattè, tiene como principal objetivo publicar, por primera vez, de forma completa y en ediciones críticas, la obra dramática de este autor madrileño. En los anteriores volúmenes se publicaron las comedias de los dos tomos que vieron la luz entre 1635 y 1638 con la autorización del dramaturgo y su padre, el editor Alonso Pérez. Con este volumen, cuyo editor general es David Arbesú, se inicia la siguiente etapa de esta serie, en la que se recogen las comedias de Pérez de Montalbán aparecidas en otras colecciones y en sueltas.

La primera comedia es Morir y disimular, editada por Claudia Demattè. Se suele considerar, a partir de una afirmación de Francisco de Quintana en el prólogo del Segundo tomo, que Pérez de Montalbán la compuso cuando tenía diecisiete años; sin embargo, como aclara la editora, tal afirmación se refiere a una de las comedias contenida en dicho tomo. Con todo, esta comedia sí habría sido compuesta tempranamente. Apoyándose en lo propuesto por Victor Dixon, Demattè la data antes del verano de 1618. En dicha fecha el madrileño tenía diecisiete años, si consideramos que habría nacido en julio o agosto de 1601, y llevaba ya seis de ellos estudiando en la Universidad de Alcalá de Henares. Fuera de El valiente más dichoso (parcialmente ambientada en Inglaterra), Morir y disimular es la única co- 
media de Pérez de Montalbán ubicada completamente en dicho país. No obstante, la ambientación es prácticamente indefinida, pues lo único que la ancla ahí es la participación del príncipe de Inglaterra. Este pretende a Clavela, quien dos años atrás se casó en secreto con Félix, un general, debido al odio entre sus familias. Por ello, Clavela tiene que soportar que su hermana Aurora declare que ama a su esposo, lo que se complica más cuando Félix, ausente a causa de la guerra, retorna y la encuentra en compañía del príncipe. Al final, se revela el matrimonio y el príncipe ofrece su mano a Aurora.

Sobre la transmisión textual, Demattè considera que las dos sueltas que se conservan (la del Institut del Teatre de Barcelona y la de la Biblioteca Nacional de España) provienen de un mismo texto impreso. En todo caso, de acuerdo con el cotejo realizado, la suelta de Barcelona es la que reproduce mejor el texto. En lo que se refiere a la recepción, la editora no ha encontrado constancia de representaciones en España (lo que se repetirá en el caso de Gravedad en Villaverde) y, siguiendo el inventario de Guillermo Lohmann Villena y Ricardo Moglia, anota que habría sido representada en Lima en 1731 (p. 16). Sin embargo, como José Antonio Rodríguez Garrido ha advertido, este inventario y el de Everett W. Hesse son defectuosos, por lo que se trata de un dato posiblemente erróneo («Recepción, apropiación y usos del teatro del Siglo de Oro en el Perú», en El teatro del Siglo de Oro al otro lado del Atlántico, ed. Germán Vega García-Luengos y Mar Zubieta, Madrid, Compañía Nacional de Teatro Clásico,2014, pp. 185-237, en particular pp. 207-208).

Gravedad en Villaverde, editada por David Arbesú, es una adaptación de la novela ejemplar La villana de Pinto (1624) del propio Pérez de Montalbán. Junto con su novela, el dramaturgo también habría tomado como fuente para la composición de esta pieza la relación de la Fiesta que se hizo en Aranjuez a los años del rey nuestro señor don Felipe IIII de (1623) de Antonio Hurtado de Mendoza. Estas celebraciones (que por diversos motivos cobraron singular fama en la época) son evocadas por el personaje de Silvia, quien realiza una detallada descripción que sigue dichas «relaciones tan discretas» (v. 196). A partir de estos datos y otras referencias metaliterarias, Arbesú data la comedia en 1624 o poco después. Sobre el argumento: durante las fiestas de Aranjuez, don Diego se enamora de Silvia, una labradora, por lo que regresa a Villaverde, pero disfrazado como el labrador Lorenzo. Debido a los violentos celos de Riselo, la labradora solicita a Feniso, su padre, que la case con su amado Lorenzo, pero este la disuade de ello al revelarle su origen noble. Por su parte, don Diego recibe la noticia de que el rey le ha entregado una compañía de soldados y una encomienda. Tras dar celos a Silvia, quien le ha pedido que se olvide de ella, vuelve a la corte. Ahí los dos amantes se reencuentran bajo sus verdaderas identidades y, tras algunos enredos más, se reconocen y acaban juntos. En relación con la transmisión del texto, se cuenta con dos testimonios: uno se encuentra en la Parte nona de comedias escogidas (1657) y el otro es una suelta del siglo XVII. Esta última, de acuerdo con el estema de Arbesú, se habría basado en el texto de la parte.

A diferencia de las anteriores comedias, la última de este volumen, La más constante mujer, fue compuesta en la madurez de Pérez de Montalbán y se trata de una de sus comedias más famosas. Fue publicada por primera vez en 1632 
en Para todos: ejemplos morales, humanos y divinos durante la prohibición de la composición y publicación de piezas teatrales ordenada por el Consejo de Castilla en 1625; de ahí que apareciese en una miscelánea, estrategia empleada por los dramaturgos de la época para camuflar la impresión de sus comedias. El tema de esta comedia palatina es el desdichado amor entre los milaneses Carlos Esforcia e Isabel Borromeo, que no puede consumarse en el matrimonio debido a la rivalidad entre sus familias. Separados por el Duque de Milán y Rosaura, la hermana de este, Isabel se mantiene constante en su amor por Carlos, incluso ante la amenaza del Duque de violarla, y no duda en tomar la espada para atacar a los hombres que pretenden asesinar a su amado. Tal constancia hace que el Duque finalmente la libere y permita su boda con Carlos.

Debido al éxito de La más constante mujer, se imprimió en numerosas ocasiones. Además de en la miscelánea mencionada, apareció en diferentes colecciones de comedias, así como en forma de suelta. Para esta edición, Philip Allen ha dejado de lado el manuscrito conservado en la Biblioteca Nacional de España, que presenta «una lectura tan distinta [...] que merecería una edición aparte» (p. 211). Por ello, en su estema los testimonios de Para todos y la Parte XXV de diferentes autores (Zaragoza, 1632) aparecen como los descendientes más directos del original perdido.

Con respecto a los textos editados, estos han sido modernizado en lo que se refiere a las grafías sin relevancia fonética; del mismo modo, la puntuación y la ortografía se han ajustado a las normas actuales. Se incluyen los respectivos aparatos de variantes y la anotación en general es precisa, pero creo que faltan algunas notas. Por ejemplo, en Gravedad en Villaverde se podría haber indicado que las plumas (v. 326) son un atributo propio del vestido del soldado y relacionado con la arrogancia, de ahí que el supuesto hijo de Albano se despoje de ellas (así como de su «flandesco sombrero», v. 327, tampoco anotado) para tomar las humildes ropas del labrador. Asimismo, si bien se anota en la última comedia, La más constante mujer, el motivo poético de la mariposa abrasada por el fuego del amor (p. 221, nota vv. 100-103), es omitido en su primera aparición en Morir y disimular:

\author{
¿Por alas batiendo flores \\ la mariposa que ama, \\ no galantea la llama \\ hasta abrasarse de amores? (p. 23, vv. 211-214).
}

En el citado pasaje, la coma al final del v. 212 es errónea, pues separa el sujeto del predicado. Además, en Morir y disimular tampoco se intenta aclarar los vv. 581582: «una dueña mucho más / que un saz a morir condena», que se explican a partir de la relación del sauce con la muerte.

A pesar de los anteriores reparos, no cabe duda de que el trabajo de Demattè, Arbesú y Allen supone una importante contribución para los estudios del teatro del Siglo de Oro. A los tres debemos agradecer por continuar con la segunda etapa de este relevante proyecto que busca ofrecernos la edición completa y crítica de la producción dramática de Pérez de Montalbán. 